\title{
LA CRÍTICA DE MARX AL ESTADO DE DERECHO: HORIZONTES PARA LA EMANCIPACIÓN JURÍDICA
}

\section{Autor: Octavio Martínez Mi- chel}

Estudiante de doctorado del Programa de Humanidades, Universidad Autónoma Metropolitana, Unidad Iztapalapa, Profesor titular de Historia del Derecho y Filosofía del Derecho en la Universidad del Claustro de Sor Juana. Correo: flanger83@gmail. com.

https://orcid.org/0000-0003-1621-3492

\author{
Marx's critique on the Rule of Law: \\ horizons for legal emancipation
}

Fecha de recepción: 2 de marzo de 2018 Fecha de aceptación: 29 de agosto de 2019 la apuesta de Marx por un hombre nuevo y por un Estado comunista donde los seres humanos estarían libres de las ataduras tradicionales implicaba un rechazo a las herramientas jurídicas como medio para la emancipación. En efecto, la crítica hecha por Marx a los derechos humanos y el Estado de derecho en La Cuestión Judía, La Crítica al Programa de Gotha, El Manifiesto Comunista, así como en algunas partes de El Capital nos deja claro que el filósofo alemán miraba con sospecha las instituciones liberales y que en parte las conceptualizaba como instrumentos de dominación.

Ahora, a pesar de que hay muchos fragmentos que pueden apoyar esta interpretación, creemos que ha sido una postura poco provechosa para el marxismo en los siglos XX y XXI, tomar la crítica de Marx a las instituciones jurídicas liberales como si se tratara de un rechazo total al derecho mismo. Desde nuestra perspectiva, es posible presentar una interpretación de Marx en la que el derecho aparezca como un instrumento importante para la emancipación. Esto implica colocar a Marx como un pensador que en el más puro estilo de la Ilustración, planteaba la crítica al derecho como un camino necesario para eliminar las máscaras que nos ocultaban la verdad, pero no como el camino para la destrucción del derecho.

Así, el objetivo del siguiente trabajo es mostrar que la crítica de Marx, si se toma desde una óptica ilustrada - republicana, nos permite pensar caminos para la emancipación sin renunciar al derecho.

Palabras clave: Estado de derecho; derechos humanos; liberalismo; llustración; emancipación.

\begin{abstract}
In the history of law it's a common place to take Karl Marx as a profound critic of human rights and the rule of law. At the same time, it has also been common to read this criticism as a total dismissal of the law. Regularly, it is emphasized that Marx's commitment to the concept of New Man and a Communist State where human beings would be free from traditional ties implied a rejection of legal tools as a means to emancipation. Indeed, Marx's critique of human rights and the rule of law in On the Jewish Question, Critique of the Gotha Programme, The Communist Manifesto, as well as in some parts of Capital make it clear to us that the German philosopher looked with suspicion the legal institutions of liberalism and partly conceptualized them as instruments of domination.

Although there are many passages that can support this view, we believe that Marx's criticism of liberal institutions as a total rejection of the law itself, has been an unhelpful position for Marxism in the 20th and 21st centuries. From our point of view, it's possible to present an interpretation of Marx in which law appears as an important instrument for emancipation. This implies placing Marx as a thinker who, in the purest style of the Enlightenment, raised the criticism of law as a necessary way to eliminate the masks that concealed from us the truth, but not as the way to the destruction of the law. Thus, the objective of the following work is to show that Marx's critique, if taken from an illustrated - republican perspective, allows us to think of ways for emancipation without renouncing the law.
\end{abstract}

Key-words: Rule of law; human rights; liberalism; Enlightenment; emancipation.

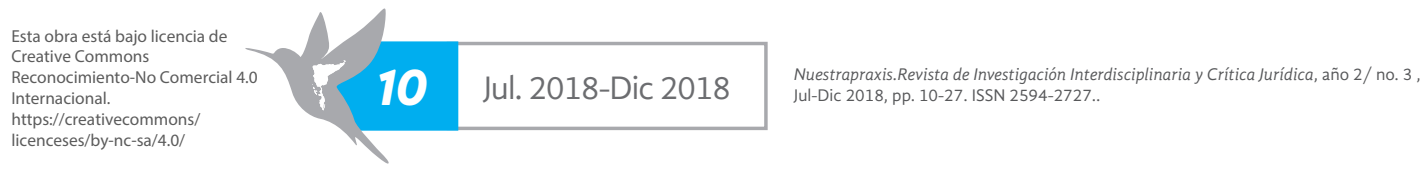




\section{1.- Anotaciones preliminares}

$P$ ara la historia ha trascendido la idea de que Marx concebía el modelo de Estado de derecho como un producto específico de la dominación política burguesa. Siendo esto así, el Estado de derecho se caracterizaría por ser el espacio jurídico-político donde la clase burguesa expresa en términos legales su dominación. Así, siguiendo la lógica de esta crítica, los derechos y las instituciones estarian diseñadas para reproducir una dinámica de que dará siempre primacía a los propietarios frente a los trabajadores 0 , si se prefiere, a los capitalistas frente al proletariado. Esto nos llevaría a la conclusión de que el derecho es un instrumento de dominación de clase que tendría que eliminarse en la sociedad comunista.

Ciertamente hay pasajes de la obra de Marx que presentan al derecho como un instrumento de dominación ligado directamente a la clase social que ejerce el poder y pasajes que presentan al Estado de derecho (burgués, liberal o capitalista) como un entramado institucional en el que se hace patente el predominio de la burguesía en la dirección del Estado. ${ }^{1}$ Ahora, aunque estos pasajes expliquen en parte el escepticismo que cierta tradición marxista (especialmente la soviética) mostró frente al derecho, es importante considerar que a su lado las corrientes occidentales marxistas y la socialdemocracia europea han buscado reiteradamente rehabilitar un "Marx llustrado", crítico con el derecho, pero a la vez consciente de los potenciales emancipadores del mismo. Esta última interpretación la comparten no sólo marxistas occidentales, sino también intelectuales ajenos a la tradición marxista como lan Shapiro. ${ }^{2}$

Desde nuestra perspectiva, la interpretación occidental de la postura de Marx frente al derecho resulta la más relevante respecto a la discusión contemporánea del Estado de derecho y los derechos humanos. Según esto último, la lectura crítico - ilustrada de Marx sobre el derecho, permitiría expresar interrogantes respecto a los presupuestos de la ciencia jurídica (neutralidad del derecho, igualdad abstracta, etc.) sin que ello implicara la renuncia a las batallas jurídicas por la libertad. Así evitamos postular la construcción de una sociedad idílica como alternativa al derecho moderno, lo que, tal y cómo dice Carlos Fernández Liria, nos condenaría a recurrir una vez más a la idea de que el nuevo hombre de Marx y de la tradición socialista, es uno que no requiere ni del derecho, ni de las instituciones para lograr su emancipación.

La revisión de la posición de Marx y de quienes intentan interpretarlo como un autor ilustrado - republicano resulta valiosa porque nos permite postular al Estado de derecho en una dimensión democrático -igualitaria que resulta una alternativa sugerente frente al modelo formal de Estado de derecho del liberalismo. Si bien Marx no nos proporciona un marco conceptual sistemático de Estado de derecho, sí nos proporciona elementos clave para poder avanzar una teoría del Estado democrático de derecho desde coordenadas crítico-socialistas, lo que nos aportaría puntos clave para poder combatir el robusto aparato teórico liberal del Estado de derecho.

A continuación expondremos los pormenores de la crítica elaborada por Marx pero antes es pertinente subrayar que, tal y como afirma Robert Fine en su artículo Marxism and the Social Theory of Law, la crítica de Marx debe considerarse como una posición inacabada. ${ }^{3}$ Esto es,

1- Al menos podemos encontrar esta posición en Sobre la Cuestión Judía, Crítica a la Filosofía del Derecho de Hegel, El Manifiesto Comunista y la Crítica al Programa de Gotha.

2- Cfr. Shapiro, Ian, Los Fundamentos Morales de la Política, Ciudad de México, El Colegio de México, 2007.

3- Ver, Fine, Robert, "Marxism and the Social Theory of Law" en Law and Social Theory, Max Travers, Reza Banakar (eds.), Oregon, 
aunque existen textos en los que Marx declara que estaba en sus intenciones hacer una crítica sistemática sobre el derecho, ${ }^{4}$ lo cierto es que el material con el que contamos para presentar su posición consta predominantemente de textos de juventud dedicados al derecho y anotaciones dispersas a lo largo de su obra. Esto, si bien presenta una dificultad interpretativa, no le quita importancia a la crítica. La disperión del argumento no implica desarticulación. Marx quería realizar una crítica sistemática del derecho, pero la tarea de la crítica de la economía política ya no lo permitió. ${ }^{5}$ Una vez dicho esto podemos comenzar la reconstrucción de la crítica de Marx.

\section{2.- La crítica a los derechos humanos}

Los puntos centrales de la posición marxiana respecto al Estado de derecho, giran en torno a la crítica a los derechos humanos y la crítica al Estado. En ambos casos Marx sospecha que hay una teoría que está encubriendo una realidad de opresión. Además, en ambos casos se ejecutan separaciones que impiden la emancipación del ser humano: se separa el hombre abstracto respecto a su comunidad (derechos humanos) y se separa la sociedad civil respecto a la sociedad política (teoría del Estado).

En el caso de los derechos humanos el postulado de un hombre abstracto con derechos universales encubre una desigualdad observable en el desarrollo de los individuos: el derecho de libertad por ejemplo no puede ser ejercido de la misma forma por un propietario (ya sea pequeñoburgués o capitalista) que por un trabajador. En el caso del Estado, el postulado de una neutralidad política, desde la perspectiva de Marx, encubre el hecho de que existe una clase dominante que dirige el rumbo de la actividad estatal.

Decíamos que además del encubrimiento, Marx explica que tanto la teoría de los derechos humanos como la del Estado operan una separación que impide la emancipación de los seres humanos. Según esto, los derechos configuran un hombre egoísta separado de su comunidad, ${ }^{6}$ mientras el Estado liberal construye un orden institucional donde el Estado se encuentra separado de la sociedad (separación entre sociedad política y sociedad civil) que tiene como finalidad que el Estado no intervenga en la esfera privada de la sociedad. ${ }^{7}$

El encubrimiento y la separación los ha operado la clase burguesa después de haberse liberado tanto de los vínculos tradicionales a los que la sometía el feudalismo, como de los abusos de la monarquía absoluta. Esta circunstancia revela que a pesar de que la burguesía es una clase revolucionaria, la emancipación de los seres humanos no podrá realizarse haciendo adecuaciones

Hart Publishing, 2013, p. 101

4- Cfr. Karl Marx, Economic \& Philosophic Manuscripts of 1844, Moscow, Progress Publishers, 1959, p. 1: "I shall therefore publish the critique of law, ethics, politics, etc., in a series of distinct, independent pamphlets, and afterwards try in a special work to present them again as a connected whole showing the interrelationship of the separate parts, and lastly attempt a critique of the speculative elaboration of that material. For this reason it will be found that the interconnection between political economy and the state, law, ethics, civil life, etc., is touched upon in the present work only to the extent to which political economy itself expressly touches upon these subjects".

5- Ver, Fine, Robert, "Marxism and the Social Theory of Law", op.cit.p.102

6- Marx, Karl, "Sobre la cuestión judía” en Escritos de juventud sobre el derecho, Madrid, Anthropos, 2008, p. 181.

7- Marx, Karl, "Sobre la cuestión judía”, op.cit., p. 180. 
al Estado de derecho, sino que se requiere una revolución proletaria que permita eliminar las desigualdades. ${ }^{8}$

Pero veamos más a detalle la posición de Marx en ambos sentidos. Respecto a la posición que toma Marx en cuanto a los derechos humanos, Oskar Negt ha explicado que no se trata de una posición simplista o de una sola vía, por el contrario: "[...] en la Declaración de los derechos del hombre y el ciudadano de 1791 Marx puede encontrar elementos emancipadores en los derechos de participación estatales, pero ahí donde se trata de los derechos humanos ve en ellos única y exclusivamente el impulso a desarrollarse de la propiedad privada". ${ }^{9}$ De tal suerte que la postura marxiana no es la de una crítica lisa y llana sobre lo que concebimos como derechos humanos, sino una crítica específica con la parte de las declaraciones de derechos que postulan la propiedad privada (en especial la capitalista) como el centro de gravedad.

En ese sentido la crítica no es a los derechos humanos de forma general, sino a éstos como apoyo de un sistema económico que no podría garantizar la emancipación de la humanidad. Según Marx, la igualdad y la libertad estipuladas por las declaraciones de derechos del siglo XVIII apuntan al burgués y no al ser humano. Esto es, los derechos van dirigidos a los propietarios que son quienes pueden ejercitar la libertad en la sociedad civil mercantilizada y presuponerse en condiciones de igualdad con sus pares. Más aún, son ellos quienes pueden ejercitar con mayor efectividad los derechos políticos pues con frecuencia estos derechos se encuentran ligados a la posesión de una propiedad privada. Quien no posee mercancías para intercambiar se encuentra excluido de esa dinámica jurídica de libertad y equidad. ${ }^{10}$ Para Negt, Marx está haciendo explícita la dependencia del ser humano a las condiciones sociales y denunciando que el capitalismo hace cada vez más difícil "una ordenación de la sociedad basada en la paz y determinada por el derecho y la moral". ${ }^{11}$ Esto porque el ámbito de la sociedad civil -donde se hacen efectivos los derechos de igualdad y libertad- es un ámbito de lucha donde hay muchos seres humanos excluidos de los derechos y explotados por la ficción filosófica del hombre abstracto que ha sido libre de contratar.

Esta es una posición que se expresa ya claramente en el artículo de Marx titulado "Sobre la Cuestión Judía" publicado en 1843. En él, caracteriza la libertad como el derecho a la separación de un hombre respecto otro hombre, lo que en sentido práctico no sería otra cosa que el derecho a la propiedad privada que, en términos de Marx, no es otra cosa que el derecho al egoísmo o al auto-interés:

El derecho humano de la propiedad privada es, pues, el derecho a disfrutar de su patrimonio y a disponer de él arbitrariamente (a son gré), sin atender a los demás hombres, independientemente de la

\footnotetext{
8- Ver, Habermas, Jürgen, Teoría y Praxis, Barcelona, Altaya, 1999, p. 115.

9- Negt, Oskar, Kant y Marx. Un Diálogo entre Épocas, Madrid, Trotta, 2004, p. 39
}

10- Al respecto es importante anotar que la crítica de Marx sólo es válida respecto a la fase del desarrollo del capitalismo que él experimentó. Según Habermas "actualmente ya no se podría afirmar que los derechos se fundamentan en el tráfico mercantil, sino en la realización democrática de todas las organizaciones que actúan en referencia al Estado". Así, si bien las características del derecho civil -palpables en documentos como el Código Napoleón de 1804- pueden dar sustento a la perspectiva marxiana, un análisis detallado del desarrollo de los derechos humanos no permite sostener las mismas conclusiones que Marx sostuvo. Con todo, Habermas enfatiza que ello no debe hacernos perder de vista que la crítica elaborada por Marx permitió comprender que el derecho formal no puede separarse de la conexión concreta de intereses sociales e históricos. Ver, Habermas, Jürgen, Teoría y Praxis..., op.cit., pp. 118 - 119.

11- Negt, Oskar, Kant y Marx. Un diálogo entre épocas..., op.cit., pp. 66-67 
sociedad, el derecho del interés personal. Aquella libertad individual, así como esta aplicación de la misma, constituye el fundamento de la sociedad burguesa, que hace que todo hombre encuentre en otros hombres no la realización, sino más bien, la limitación de su libertad. ${ }^{12}$

En el mismo sentido se expresa Marx sobre la igualdad y sobre la seguridad. La primera consiste en la garantía para todo hombre (burgués) de ser una mónada aislada, replegada sobre sí misma, mientras la segunda implica la garantía de que el egoísmo será defendido por un aparato de policía. De ello se deriva la conclusión devastadora de que "ninguno de los derechos humanos va, por tanto, más allá del hombre egoísta, del hombre tal y como es miembro de la sociedad burguesa, es decir, del individuo replegado en sí mismo, en su interés privado y en su arbitrariedad privada, y separado de la comunidad". ${ }^{13}$

Aún así, Robert Fine nos advierte que estas afirmaciones no deben llevarnos a pensar que Marx no consideraba los derechos de libertad e igualdad como un enorme avance civilizatorio. ${ }^{14}$ Por el contrario, según Fine, en El Capital se presentan como formas jurídicas que ya no aparecen ni como un ideal, ni como forma vacía. Equidad y libertad son formas jurídicas que presuponen relaciones de producción capitalistas, es decir, no pueden tomarse como categorías intemporales o como neutrales respecto a la tensión entre las clases sociales, sin embargo, son formas jurídicas que revelan que al menos los propietarios se han reconocido entre sí como personas que no han de arrebatarse sus bienes de forma violenta, sino que han de establecer relaciones de intercambio.

De tal suerte, la crítica de Marx a los derechos humanos resulta más compleja que un simple descrédito a las categorías jurídicas burguesas. De hecho, tal y como sugiere Oskar Negt, si seguimos la argumentación dialéctica de Marx, deberíamos concluir que el socialismo no se trata de negar todo aquello que haya venido del capitalismo, sino de aprovechar las cosechas de éste para un mejor reparto y para la consolidación de la dignidad humana. ${ }^{15}$ Por ello, en el Estado socialista los derechos no deberían barrerse como consideró Evgeny Pashukanis, sino más bien aprovecharse para la lucha por la emancipación de la humanidad.

Con todo, como señala Habermas, es difícil borrar la huella que dejaron los pasajes en los que Marx claramente desacreditaba los derechos humanos. Dicho descrédito, desde la óptica del filósofo alemán, provocó la disociación entre derecho natural y revolución. Esto significó que "los partidos de una guerra civil internacionalizada dividieron el legado de un modo fatalmente unívoco: una parte recibió la herencia de la revolución, la otra, la ideología del derecho natural”. ${ }^{16}$

\footnotetext{
12- Al respecto es importante anotar que la crítica de Marx sólo es válida respecto a la fase del desarrollo del capitalismo que él experimentó. Según Habermas "actualmente ya no se podría afirmar que los derechos se fundamentan en el tráfico mercantil, sino en la realización democrática de todas las organizaciones que actúan en referencia al Estado". Así, si bien las características del derecho civil -palpables en documentos como el Código Napoleón de 1804- pueden dar sustento a la perspectiva marxiana, un análisis detallado del desarrollo de los derechos humanos no permite sostener las mismas conclusiones que Marx sostuvo. Con todo, Habermas enfatiza que ello no debe hacernos perder de vista que la crítica elaborada por Marx permitió comprender que el derecho formal no puede separarse de la conexión concreta de intereses sociales e históricos. Ver, Habermas, Jürgen, Teoría y Praxis..., op.cit., pp. 118 - 119.

13- Marx, Karl, "Sobre la Cuestión Judía”, op.cit., p. 192.

14- Ver, Fine, Robert, Democracy and the Rule of Law: Marx's Critique of the Legal Form, USA, Balckburn Press, 2002, pp. $108-109$.

15- Ver, Negt, Oskar, Kant y Marx. Un diálogo entre épocas..., op.cit., p. 90.

16- Habermas, Jürgen, Teoría y Praxis..., op.cit., p. 116.
} 
Lo fatal en esto es que, la crítica de Marx interpretada de forma malintencionada, jugó un papel fundamental para el asentamiento del stalinismo.

\section{3.- La separación entre la sociedad civil y sociedad política. Crítica a la teoría del Estado}

Como mencionamos párrafos atrás, una de las preocupaciones de Marx respecto a la configuración del derecho moderno es que éste se erige desde un Estado (sociedad política) que se separa de la sociedad civil. El problema fundamental en este sentido es que la teoría moderna del Estado ha pretendido que éste es una institución idónea para la expresión del interés general, pero pretende defender dicho interés proclamando que la sociedad civil-espacio donde se desarrollan las relaciones entre particulares- debe quedar intocada por el poder del Estado. Dice Marx:

La revolución política... [que] elevó los asuntos del Estado a asuntos del pueblo y que constituyó el Estado político como incumbencia general, es decir, como Estado real, destruyó necesariamente todos los estamentos, corporaciones, gremios y privilegios, que eran otras tantas expresiones de la separación entre el pueblo y su comunidad. La revolución política suprimió, con ello, el carácter político de la sociedad burguesa... Al sacudirse el yugo político se sacudieron, al mismo tiempo, las ataduras que apresaban el espíritu egoísta de la sociedad civil. ${ }^{17}$

De tal suerte que la teoría del Estado, según Marx, se sustenta en una difícil tensión entre el campo de lo público-estatal y el campo de lo privado-social, en la que, la garantía de un espacio privado intocable del que todos los ciudadanos son partícipes, resulta en la liberación del espíritu egoísta de la sociedad civil. El problema es, al igual que en el caso de los derechos humanos, que esta teoría opera un enmascaramiento en el que la protección del espacio privado de todos los ciudadanos, se traduce en la protección del espacio privado de la clase burguesa. Así, formalmente el Estado se encuentra limitado primordialmente para intervenir en la vida privada de todos los ciudadanos, pero materialmente desprovisto de los medios para la protección de todos los individuos.

El enmascaramiento se hace más claro si se toma como ejemplo la situación de los trabajadores, quienes para incluirse en ese todo que representa la ciudadanía, se asumen como propietarios de su fuerza de trabajo y, por tanto, como individuos libres de contratar con el capitalista la renta de su propiedad. Así, el contrato puede estipular condiciones injustas para los obreros (ausencia de límites a los horarios de trabajo, salarios que no permiten la supervivencia, falta de condiciones de seguridad en la industria, etc.), sin que el Estado pueda intervenir para regular dichas relaciones contractuales para intentar paliar dicha injusticia. Al tratarse de relaciones contractuales hechas libremente por individuos dentro de la sociedad civil, toda intromisión del Estado sería calificada como despótica. ${ }^{18}$ Esto según Marx reafirma la idea que la igualdad de iure encubre una desigualdad de facto.

17- Marx, Karl, “Sobre la Cuestión Judía”, op.cit., pp. 194-195.

18- Al respecto vale la pena recordar que, tal y como afirma Gerardo Pisarello, el liberalismo monárquico se alió a los intereses capitalistas negándose a intervenir entre el patrón y el obrero en favor de la "libre empresa". Cfr. Gerardo Pisarello, Un Largo Termidor, Madrid, Trotta, 2011, pp. 94 - 95 
Desde la óptica de Michel Miaille esta crítica es igualmente aplicable a la historia del derecho constitucional. Si revisamos dicha historia nos encontraremos que en ella impera una "singular mistificación" con la que se pretende que por el sólo hecho de expresar un orden jurídico éste se vuelve realidad ${ }^{19}$, dicha mistificación, según Miaille, quedó en bancarrota después de que la sociología (especialmente la marxista) empezó a revisar el derecho constitucional:

En una palabra, se descubrió, de cierta manera, que "por debajo" del derecho ¡estaba la realidad! Descubrimiento que resultó aún más obvio con la experiencia de los países de independencia reciente: los chascos sufridos por esos nuevos Estados, mostraban a las claras la distancia que puede separar al derecho constitucional de la realidad política. ${ }^{20}$

Ahora volvamos al siglo XIX. La crítica al Estado de Marx presenta facetas tanto hegelianas como anti-hegelianas. Marx sigue a su maestro en la crítica que aquel hace al predominio de los intereses privados (asimilables para Hegel a los intereses feudales) frente al interés general (estatal), pero se separa de él respecto a la expectativa de poder reconciliar lo público y lo privado. Al respecto dice Miaille que el Estado, en la teoría de Marx, es el signo de la enajenación política que oculta bajo nociones como interés general y ciudadano las verdaderas contradicciones (oposición de intereses) de la sociedad civil. ${ }^{21}$ Según esto, es la vida económica el fundamento contradictorio sobre el cual se levanta el edificio político-jurídico. El Estado, recuerda Miaille no reduce las contradicciones, sino acaso las contiene. ${ }^{22}$

Así, Marx reconoce la necesidad de la crítica hegeliana a la situación política alemana en el siglo XIX, pues justamente atacaba el fondo del problema de la emancipación en la Alemania de la época: la ausencia de Estado. La crítica hegeliana hacía patente que "el Estado como mediación necesaria de los intereses de todos, situado por encima de todos, aparece como una verdadera superación de la sociedad arcaica". ${ }^{23}$ Sin embargo, el problema para Marx con la teoría hegeliana es la tendencia a idealizar el Estado como el espacio para la realización de la libertad, pues esto oculta una realidad:

19- Ver, Miaille, Michel, El Estado del Derecho, Universidad Autónoma de Puebla, Puebla, 1985, pp. 18 - 20. Curiosamente esta posición contra la mistificación del derecho constitucional, la comparten con los marxistas juristas conservadores contemporáneos como el juez de la Corte Constitucional Italiana Paolo Grossi. Al respecto vale la pena revisar tanto las argumentaciones que hace el juez florentino en: Mitología Jurídica de la Modernidad, Madrid, Trotta, 2003 y en La primera lección del derecho, Madrid, Marcial Pons, 2006.

20- Miaille, Michel, El Estado del Derecho..., op.cit., p. 20

21- Ver, Miaille, Michel, El Estado del Derecho...., op.cit., pp. 159 - 160

22- Miaille lleva la crítica de Marx al Estado un poco más lejos y argumenta que no puede explicarse el Estado como forma política dominante sin el ascenso de la burguesía. Según esto, la burguesía requería del Estado para liberarse de las ataduras del orden feudal tradicional. Así, la burguesía incluso fue capaz de aliarse con monarcas absolutos con el objetivo de eliminar el predominio de los señores feudales. Una vez que el Estado (absoluto) puede afirmarse como garante del bien común, las pasiones particularistas de los señores quedan neutralizadas. Desde la perspectiva de Miaille en el proceso dialéctico de ascenso de la burguesía, este era un paso necesario para finalmente tomar las riendas de la dirección del Estado. Cfr. Miaille, Michel, El Estado del Derecho, op.cit., pp. 63 - 66

23- Miaille, Michel, El Estado del Derecho..., op.cit., p. 159 
[...] las contradicciones que entraña y revela la sociedad civil, lejos de ser abolidas o superadas por el Estado, son simplemente ocultadas: el ciudadano, que está situado en un nivel supuestamente superior, se opone al hombre. Pero esta separación no suprime de modo alguno las contradicciones entre los hombres. De ahí que el Estado sea el "cielo" ideal, mientras que los verdaderos problemas de la "tierra" permanecen sin solución. ${ }^{24}$

En el fondo, como menciona Robert Fine, la pretensión de Marx en la crítica que realiza a su maestro es la de fundamentar un Estado con mayores credenciales democráticas. Así, el núcleo de la crítica marxiana sería el siguiente:

[Marx] atacó la intrusión del interés privado en la dirección del Estado, que Hegel santificaba bajo la ilusión de que era el Estado quien se estaba entrometiendo en los intereses privados; y atacó la alienación del Estado de la voluntad real de un pueblo real, que Hegel santificaba como la realización de la voluntad racional de un pueblo racional. En cualquiera de los dos casos, ya fuera a través de la subordinación del Estado a los intereses privados o a través de la elevación del Estado como un poder especial por encima del pueblo, la universalidad del Estado estaba corrompida. El ideal hegeliano del Estado mostraba síntomas de ambas cosas. ${ }^{25}$

De esta manera Marx veía en la teoría de Hegel una construcción del Estado donde todo se encuentra de cabeza: "la conciencia empírica -lo que las personas realmente piensan y desean- está subordinada a una conciencia racional, i.e. lo que deben pensar, hacer y querer si fueran racionales". ${ }^{26}$ Según Marx esto podía encontrarse claramente en los postulados de Hegel sobre la Constitución, los cuales había que criticar poniendo a las personas por encima de la Constitución, pues "no es la Constitución quien crea el pueblo, sino el pueblo quien crea la constitución. Y así como las personas crean la constitución, también pueden desmantelarla y reemplazarla". ${ }^{27}$ Tal y como dice Marx: "En la democracia la Constitución, la Ley, el mismo Estado no es más que una característica que el pueblo se da a sí mismo y contenido concreto suyo, en cuanto ese contenido es Constitución". ${ }^{28}$ Ver a Marx desde está perspectiva nos recuerda los postulados republicanos de Rousseau en El Contrato Social donde afirma que la constitución no podría estar nunca por encima del pueblo:

24- Miaille, Michel, El Estado del Derecho..., op.cit., p. 159

25- Fine, Robert, Democracy and the Rule of Law..., op.cit., p. 70. Todas las traducciones que aparezcan de este texto son de mi autoría.

26- Fine, Robert, Democracy and the Rule of Law..., op.cit., p.72.

27- Fine, Robert, Democracy and the Rule of Law, op.cit., p. 72.

28- Marx, Karl, Crítica a la Filosofía del Estado de Hegel, Madrid, Editorial Biblioteca Nueva, 2010, p. 66. 
[...] la deliberación pública, que puede implicar la obligación de todos los súbditos hacia el soberano, debido a las dos diferentes relaciones bajo las cuales cada uno de ellos puede ser considerado [como miembro del soberano o como miembro del Estado], no puede, por la razón contraria, obligar al soberano para consigo mismo, y que, por tanto, es contrario a la naturaleza del cuerpo político que el soberano se imponga una ley que no pueda infringir. Al no poder considerarse más que una sola relación, se encuentra en el caso de un particular que contrata consigo mismo, lo que demuestra que no hay ni puede haber ningún tipo de ley fundamental obligatoria para todo el cuerpo del pueblo, ni si quiera el contrato social. ${ }^{29}$

Así, al criticar a Hegel, Marx coloca a la democracia como el elemento sustantivo para resolver la dependencia del hombre real al hombre abstracto, pues a la verdadera democracia pueden unirse lo universal y lo particular a través de la identificación entre el hombre y el Estado. Dice Marx:

[...] en la democracia la Constitución misma se presenta solamente como una determinación y, más precisamente, la autodeterminación del pueblo. En la monarquía tenemos al pueblo de la Constitución; en la democracia a la Constitución del pueblo. La democracia es el enigma descifrado de todas las Constituciones. Aquí la Constitución toca siempre fondo en su fundamento real, el hombre real, el pueblo real, y esto en una forma subjetiva, real y no sólo objetiva, de suyo; la Constitución es sentada como obra del pueblo. La Constitución aparece como lo que es, libre producto del hombre. También de la monarquía constitucional se podría decir en cierto modo lo mismo; pero la democracia se distingue aquí específicamente, porque en ella la Constitución nunca es más que un factor de la existencia de un pueblo: la Constitución política no forma por sí sola el Estado. Hegel parte del Estado y ve en el hombre al Estado hecho sujeto; la democracia parte del hombre y ve en el Estado al hombre objetivado. ${ }^{30}$

El republicanismo democrático o radical de Marx queda coronado según Robert Fine con la crítica a la teoría de Hegel sobre el sistema de representación política. Dicho sistema, elevaba a los diputados electos por sobre el pueblo, lo que daba por resultado que el Parlamento aparecía como el verdadero pueblo, mientras el pueblo real aparecía como una especie de masa informe. Contra ello, Marx "buscaba, primero crear el sufragio universal y la terminación de los privilegios de los terratenientes; segundo, crear un 'sufragio activo' con el cual los diputados tuvieran que rendir cuentas ante su electorado; y tercero, elevar la asamblea - como la esfera de la representación - en la totalidad del Estado político". ${ }^{31}$ Así, es en la legislatura donde encuentra Marx la esfera adecuada para ejercer la autoridad del Estado político:

29- Jean - Jacques Rousseau, Madrid, El Contrato Social, Tecnos, 1988, p. 17.

30- Marx, Karl Crítica a la Filosofía del Estado de Hegel..., op.cit., p. 99

31- Fine, Robert, Democracy and The Rule of Law..., op.cit., p. 77 
El Poder Legislativo ha hecho la Revolución francesa; allí donde, como realidad específica, ejerció la hegemonía, el Poder Legislativo ha realizado las grandes revoluciones generales de todo el organismo político. Su lucha no se ha dirigido contra la Constitución, sino contra una Constitución específica, anticuada; y es que el Poder Legislativo era precisamente el representante del pueblo, de la voluntad de la especie. El Poder Ejecutivo por el contrario ha hecho las revoluciones pequeñas, retrógradas, las reacciones; en vez de hacer la revolución por una nueva Constitución contra la vieja, se ha alzado contra la Constitución; y es que el Poder Ejecutivo era el representante de la voluntad especial, de la arbitrariedad subjetiva, del lado mágico de la voluntad. ${ }^{32}$

Según Robert Fine, pasajes como el anterior, nos permiten situar al joven Marx en una dimensión republicana radical, desde la que sería posible presentar una teoría crítica de origen marxiano que reconozca los potenciales emancipatorios del derecho. Esto es, una teoría capaz de mostrar lo que ocultan la teoría del Estado y el sistema de representación política de las monarquías constitucionales, sin renunciar a la creación de ordenamientos jurídicos emancipatorios a través de la representación popular.

Esta interpretación de Marx la comparten algunos otros autores como Carlos Fernández Liria y Luis Alegre Zahonero, quienes en su texto El Orden del Capital, sostienen que para los marxistas contemporáneos la tarea de rehabilitar al Marx más cercano a la llustración y el republicanismo radical es impostergable. Para estos pensadores españoles dicha reivindicación significaría un avance importante para la crítica contemporánea al capitalismo, pues permitiría renonocer en el derecho moderno un elemento indispensable para las luchas de emancipación. ${ }^{33}$ Antes que ellos, Edward Thompson había afirmado que el marxismo se había metido en un problema difícil al suponer que las libertades individuales y el Estado de derecho no eran otra cosa que instrumentos de dominación de clase. Desde la perspectiva de Thompson, la posición clásica (o dogmática) del marxismo frente a los derechos humanos y el Estado de derecho impedía ver que las libertades eran producto de luchas populares y que aún considerando que el derecho justifica un orden de dominación burgués también limita a la clase dominante. ${ }^{34}$

Definitivamente estas interpretaciones de Marx permitirían colocar mejor su crítica al derecho en la reflexión contemporánea sobre los derechos humanos, el Estado, la organización del poder, etc. Tal y como dice Robert Fine, la crítica marxiana al derecho, aunque inacabada, tiene como fundamento desmitificar las categorías sacrosantas de lo jurídico que podrían llevarnos a la armonía total. ${ }^{35}$ Esto, además estaría en consonancia con el Marx crítico del socialismo utópico del siglo XIX que enuncia conceptos como el de justicia eterna para criticar el capitalismo. En este sentido es famosa la crítica de Marx a la obra de Joseph Proudhon:

\footnotetext{
32- Marx, Karl, Crítica a la Filosofía del Estado de Hegel..., op.cit., p. 132

33- Ver, Fernández Liria, Carlos y Alegre Zahonero, Luis, El Orden de El Capital, Madrid, Akal, 2010, pp. 612 - 613

34- Ver, Robert Fine, Democracy and the Rule of Law..., op.cit., pp. 170 y ss.

35- Ver, Robert Fine, Marxism and the Social Theory of Law..., op.cit., pp. 100 - 106.
} 
Proudhon comienza por extraer su ideal de justicia, la "justice éternelle" [justicia eterna], de las relaciones jurídicas correspondientes a la producción de mercancías, con lo cual, digámoslo incidentalmente, aporta la consoladora prueba para todo burgués filisteo de que la forma de la producción de mercancías es tan eterna como la justicia. Luego vira en redondo y pretende modelar, con arreglo a ese ideal, la producción real de mercancías y el derecho real correspondiente a ésta. ¿Qué opinaríamos de un químico que, en vez de investigar las leyes que efectivamente rigen la asociación y disociación de la materia, y en lugar de resolver sobre la base de las mismas determinados problemas, explicara esa composición y descomposición por las "ideas eternas" de la "naturalité" [naturalidad] y la "affinité" [afinidad]? Cuando se sostiene que la "usura" contradice la "justice éternelle" [justicia eterna] y la "équité éternelle" [equidad eterna] y la "mutualíté éternelle" [reciprocidad eterna] y demás "verités éternelles" [verdades eternas], ¿sabemos algo más acerca de ella que lo que sabían los Padres de la Iglesia cuando aseguraban que contradecía la "grâce éternelle" [gracia eterna], la "foi éternelle" [fe eterna], la "volonté éternelle de Dieu" [voluntad eterna de Dios]?36

Entonces, conceptos como el de justicia eterna terminan por evadir el camino científico de la crítica de la sociedad en aras de una crítica humanista que para Marx resulta vacía y justificatoria de las relaciones de producción existentes. Esto es, la noción de Proudhon opera una abstracción que también oculta el origen humano de nociones como justicia, ley, derechos, etc. De tal suerte que, según quienes reivindican al Marx republicano radical, la forma más rica de entender la crítica al derecho es asumiendo que ésta no implica un divorcio total entre socialismo y derecho. Más bien, implica entender que tras la pretensión de desenmascarar todo lo que ocultan las teorías modernas sobre las realidades sociales, está la intención de reconocer que el derecho también moldea a las sociedades. Esto supone reconocer que tanto la economía como el derecho son expresiones de las mismas relaciones de producción y que así como los socialismos no deben desaprovechar los frutos económicos y tecnológicos que ha dejado el capitalismo, tampoco deben desaprovechar los frutos del derecho "burgués". En lo que sigue expondremos de forma más detallada esta perspectiva.

\section{4.- El Marx de la Ilustración y sus implicaciones para el derecho}

Férnandez Liria y Alegre Zahonero afirman que los teóricos liberales del derecho suelen identificar Estado de derecho y sociedad de mercado como las dos caras de la moneda de la llustración. ${ }^{37}$ Siendo esto así, los conceptos de ciudadanía y de capitalismo estarían íntimamente relacionados,

\footnotetext{
36- Marx, Karl, El Capital, Tomo I, Madrid, Siglo XXI, 2010, p. 103

37- Ver, Fernández Liria, Carlos \& Alegre Zahonero, Luis, El Orden del Capital, op. cit., pp.19 - 22; 239 -244.
} 
lo que implicaría que de la liberación de las ataduras tradicionales comunitarias de las sociedades feudales (religión, lazos de parentesco, etc.) deriva necesariamente una sociedad de mercado.

Significativamente, la tradición marxista ha compartido esta lectura de la llustración, lo que provocó entre otras cosas que el marxismo creyera que uno de los objetivos del socialismo era superar el derecho (barrerlo con todo y su egoísmo según Pashukanis). Ciertamente hay elementos en el propio Marx que apoyarían esta lectura, pues tal y como dice Habermas: "Marx, en efecto, no concibe el Estado de derecho burgués de otro modo a como este se había entendido a sí mismo: de un modo liberal". ${ }^{38}$ Según esta concepción, para Marx el Estado de derecho se presenta como el garante de un contrato de todos los miembros de la sociedad hecho para sostener las condiciones "dentro de las cuales los individuos poseen el usufructo de la contingencia. Este derecho a poder deleitarse con lo contingente dentro de los márgenes de ciertas condiciones sin ser molestado, [y que hemos] llamado hasta ahora libertad personal". ${ }^{39}$

Si a esto agregamos el hecho de que la crítica de Marx se sostenía sobre el argumento de que la economía política había sido la piedra de toque para la construcción del Estado, tenemos un panorama donde las leyes naturales de la economía deben asegurar las promesas de los derechos naturales. Así, según Habermas, la crítica a la economía política que realiza Marx tenía el objetivo de probar que el libre tráfico de propiedades privadas excluye la igualdad de oportunidades de disfrute de autonomía para todos los individuos. Si lograba esto, desenmascaraba la revolución burguesa como revolución de clase lo que llevaría aneja la conclusión de que el interés de la burguesía no es identificable con el interés de toda la sociedad y, por lo tanto, sus leyes serían solo un instrumento para perpetrar un interés de clase. ${ }^{40}$

La cuestión es que al pensar que los principios jurídicos de la sociedad moderna son identificables con el fundamento de la sociedad capitalista, el marxismo ha tenido que desarrollarse fuera de los confines de la llustración colocándose en una incómoda posición en la que, por el desprecio del concepto de ciudadanía se ve obligado a:

[...] coquetear con toda suerte de holismos y comunitarismos que, en su ensalzamiento de los valores de la cooperación y lo colectivo, estaban necesariamente abocados a fundar una especie de nueva religión. Se anunciaba, así, "un hombre nuevo" destinado, al parecer, a superar el egoísmo del individualismo burgués. [De tal suerte que el marxismo como opción política no podría postular otra cosa que un socialismo utópico y] hacer más que el ridículo al compararse con las teorizaciones del llamado "derecho burgués" que tenían lugar en el seno de la llustración. ${ }^{41}$

Esto, según Fernández y Alegre es una interpretación poco provechosa de Marx, sobre todo si pensamos que normativamente hablando, el derecho es la única institución que permite al ser humano liberarse de las ataduras del viejo orden que Marx tanto criticaba. En palabras de los autores:

38- Habermas, Jürgen, Teoría y Praxis..., op.cit., p. 113.

39- Marx, Karl, "La Ideología Alemana” en Werke, vol. III, Berlín, 1959, p. 62. Citado por Jürgen Habermas en Teoría y Praxis..., op.cit., p. 113

40- Ver, Habermas, Jürgen, Teoría y Praxis..., op.cit., p. 113

41- Fernández Liria, Carlos y Alegre Zahonero, Luis, El Orden del Capital..., p. 244 
El derecho es como una escalera -la única que ha inventado el ser humano- para escalar por encima de las servidumbres religiosas. Si se pretende subir un peldaño más alto, es inevitable volver a caer al suelo. $Y$ eso ha sido lo que, efectivamente, ha ocurrido de forma invariable. La historia dejó muy claro que más allá del derecho no se encontraba más que el más acá de la religión, la tradición y la superstición. ${ }^{42}$

Es cierto que en la teoría de Marx existe la expectativa de un "nuevo hombre", pero considerando que parte de la crítica marxiana al capitalismo es que éste impide el desarrollo de la libertad y de la razón humana, lo que habría que concluir es que cuando Marx habla de un "nuevo hombre", de un hombre emancipado de las relaciones de producción capitalista, bien podría ser el hombre republicano de la llustración. Es decir que ese "nuevo hombre" puede ser el ciudadano que participa activamente en la dirección de los asuntos del Estado y que ha logrado reconducir su egoísmo al considerar, con Rousseau, que la colegislación es la mejor de las opciones en el panorama políticolegislativo en tanto que garantiza reciprocidad y racionalidad. Dice el filósofo ginebrino:

Es decir, dándose cada uno a todos, no se da a nadie [...] Este paso del estado de naturaleza al estado civil produce en el hombre un cambio muy importante, al sustituir en su conducta la justicia al instinto, y al dar a sus acciones la moralidad que les faltaba antes. Es entonces solamente cuando la voz del deber reemplaza al impulso físico, y el derecho, al apetito, y el hombre, que hasta el momento no se había preocupado más que de sí mismo, se ve obligado a actuar conforme a otros principios y a consultar su razón en vez de seguir sus inclinaciones. ${ }^{43}$

Fernández y Alegre reconocen que desligar el concepto de ciudadanía del concepto de propiedad privada no es tarea sencilla pues todo sujeto de derecho requiere de dicha propiedad. Esto quiere decir que debemos evitar la tentación de ocultar o negar que el cuerpo es la base material de los derechos: la propiedad nos permite ser dueños de nosotros mismos y, por tanto es la condición de posibilidad para afirmarnos como ciudadanos. La carencia de un sustento desvanece las posibilidades para un individuo de tomar decisiones libremente, lo cual lo expulsa del terreno de la ciudadanía.

El problema es que, desde la óptica capitalista, todos somos propietarios de nuestra fuerza de trabajo y por lo tanto todos somos ciudadanos libres de tomar decisiones, especialmente cuando se trata de realizar relaciones contractuales. Esto, desde la perspectiva de Fernández y Alegre, es una ficción napoleónica que ha resultado muy conveniente para esconder una esclavitud de facto a través de una libertad de iure. Ningún republicano - afirman- habría aceptado la ficción de que todos somos propietarios por el sólo hecho de ser poseedores de nuestra fuerza de trabajo. A ello podría objetarse que muchos de éstos teóricos republicanos (Harrington, Montesquieu e incluso Rousseau) utilizaban esa posición para fundamentar una democracia censitaria o una república aristocrática y que frente a ellos el capitalismo ha puesto la ciudadanía al servicio de todos los

42- Fernández Liria, Carlos y Alegre Zahonero, Luis, El Orden del Capital..., op.cit., p. 244

43- Jean - Jacques Rousseau, El Contrato Social..., op.cit., pp. 15 - 19 
hombres. A lo cual, desde la perspectiva crítica de Marx, se podría responder que los republicanos aristocráticos al menos estarían evitando encubrir desigualdades sociales con entelequias jurídicas.

Así, quedaría perfectamente claro que la lucha por una democracia radical (sufragio universal, participación activa, etc.) depende no sólo del reconocimiento de derechos políticos universales, sino de la universalización de la propiedad. Es por ello que Marx insistió con tanta vehemencia en que constituir la fuerza de trabajo en mercancía sólo es posible a través de una expropiación violenta de las condiciones de trabajo de la población. Volveremos más adelante sobre este tema.

En la búsqueda del Marx republicano resultan significativas las anotaciones Oskar Negt, quien afirma que es posible encontrar en Marx ecos kantianos que deberían indicarnos que el filósofo de Renania no abandonó su herencia ilustrada - republicana y que, por tanto, podría asegurarse que la crítica marxiana al derecho no supone un desprecio por éste. Para sostener esto, Negt argumenta que la ética kantiana y la economía marxiana describen dos polos del mundo burgués que no se han superado:

Nadie ha penetrado con tanta hondura en el misterio de lo moral como Kant. Nadie en la historia europea se ha ocupado con tanta intensidad con la lógica del capital y las leyes del movimiento económico como Marx [...] Ninguno de los discursos éticos modernos puede pasarse sin una elaboración crítica de la posición kantiana; ninguna investigación actual del sistema económico, del modo de producción capitalista y de la producción de mercancías puede arreglárselas sin ocuparse con la teoría social marxista. Ambas designan de manera específica en cada caso puntos angulares del mundo burgués, cuyo horizonte, a pesar de las reiteradas manifestaciones en este sentido, no hemos cruzado en modo alguno. ${ }^{44}$

Ambos, Kant y Marx denunciaron la mercantilización del ser humano y la conversión de este en un medio para los intereses particulares y para ambos "en el progreso del conocimiento y el saber, es más, en el aprovechamiento de las disposiciones técnicas y pragmáticas de los seres humanos hay establecido un progreso en el sentido de la ilustración y la emancipación". ${ }^{45}$ Y precisamente porque compartían esta visión del mundo, los conceptos de dignidad y autonomía que Kant enunció para evitar entender al ser humano como un medio fueron un "aguijón en la carne del movimiento socialista". ${ }^{46}$ La dignidad, la libertad y los derechos humanos fueron los principales reclamos contra el régimen soviético, lo que acarreó la conclusión en algunos pensadores marxistas de occidente (especialmente dentro de la Escuela de Frankfurt) de que quitarle el gorro frigio o el traje ilustrado a Marx resultaba en un muy mal negocio. En palabras de Negt:

Cuanto mayor era la dureza con la que la ortodoxia marxista pasaba a un primer plano como doctrina económica y doctrina de la lucha de clases, tanto más decididamente se trabajó con exclusiones. Mientras la economía adoptaba el estatus de una materia dura,

\footnotetext{
44- Negt, Oskar, Kant y Marx. Un Diálogo entre Épocas..., op.cit., p. 77

45- Negt, Oskar, Op. Cit., p. 80

46- Negt, Oskar, Op. Cit., p. 71
} 
sólo accesible al análisis científico, aquellos problemas éticos de la dignidad, la justicia y en general de contemplar el socialismo como la cuestión de una conformación más humana de las cosas, fueron aherrojados cada vez con más fuerza en el ámbito del encubrimiento ideológico y del autoengaño. ${ }^{47}$

Así, la socialdemocracia europea insistió en que un Marx republicano e ilustrado bien podía criticar el derecho tanto para quitarle mistificaciones a la ciencia jurídica, como para denunciar las condiciones de desigualdad ocultas, pero que eso distaba mucho del desprecio franco y llano que habían manifestado tanto el nazismo como el stalinismo por el derecho. ${ }^{48}$

Para finalizar esta sección vale la pena anotar dos cosas. La primera, es que si bien han sido las corrientes marxistas occidentales quienes han intentado reivindicar el origen republicano e ilustrado de Marx, definitivamente no han sido exclusivamente ellas. A modo de ejemplo puede citarse la posición del filósofo estadounidense lan Shapiro:

Marx fue un producto de la llustración y como tal, estaba profundamente comprometido con el espinoso maridaje de la concepción científica de las disposiciones sociales humanas con una robusta concepción de los derechos individuales. Si bien existen diferencias entre la concepción marxista y la liberal de esas dos nociones, con demasiada frecuencia se exageran las disimilitudes y se soslayan los puntos comunes. ${ }^{49}$

La segunda cuestión que quisiera anotar es que, como dice Robert Fine, el carácter ilustrado de Marx puede verse con mayor claridad si se enfatiza la postura de Marx de que el hombre no es ni mercancía, ni sujeto abstracto. Esta idea le permite a Marx colocar al trabajador como un sujeto de derecho que puede emanciparse, pues al ser propietario de esa fuerza de trabajo ya no es un mero engranaje de la cadena productiva. De esta forma, Marx puede mantener la crítica a la equiparación de la posesión de la fuerza de trabajo con las posesiones del capitalista, sin dejar desprovisto al proletariado de medios jurídicos para encaminar la lucha de clases-50

\section{5.- Conclusión: el trabajo capitalista y los caminos de emancipación jurídica}

Dijimos párrafos atrás que parte importante de la crítica de Marx al capitalismo tenía que ver con la ficción de que capitalista y proletario realizan contratos libres en igualdad de condiciones.

\footnotetext{
47- Negt, Oskar, Kant y Marx. Un Diálogo entre Épocas..., op.cit., p. 70

48- Ver, Fine, Robert, Marxism and the Social Theory of Law..., op.cit.

49- Shapiro, Ian, Los Fundamentos Morales de la Política..., op.cit., p. 99

50- Fine, Robert, Marxism and the Social Theory of Law..., op.cit.
} 
Así, lo que hacía el derecho burgués, según Marx, es ocultar una realidad de desigualdad con una igualdad jurídica formal. Se oculta pues que lo que explica la dinámica del capitalismo es la conversión violenta de la fuerza de trabajo en mercancía. Así, dicen Fernández y Alegre, lo que pretende el capitalista es negociar con el trabajador en términos de una negociación individual. De esta manera los salarios estarían sometidos a la lógica mercantil, lo que permitiría especular con esa mercancía llamada "fuerza de trabajo" y además pagarla al precio más competitivo.

Justamente por eso, resultaron fundamentales los derechos de negociación colectiva logrados durante el siglo XX, pues ellos constituyeron un reconocimiento de las diferencias entre clases y un reconocimiento de que existen razones de peso para que el trabajo esté sometido a la lógica de los intercambios individuales. Si esa lógica no se hubiera roto, la gran mayoría de la población no podría ejercer derechos civiles.

En parte, esa lógica de someter el trabajo al mercado explica porqué Marx se dedicó gran parte de su vida a criticar las relaciones económicas dejando de lado una crítica más sistemática del derecho. Marx percibía que la esencia del "derecho igual" era la desigualdad entre trabajo y capital donde los trabajadores reciben en forma de salario el valor de su fuerza de trabajo. Así, para Marx resultaba fundamental descubrir cómo es que se había consolidado ese tipo específico de intercambio. A pesar de ello, Robert Fine asegura que en su obra podemos encontrar una crítica jurídica aneja a la crítica a las relaciones económicas de tal suerte que podríamos decir que la crítica jurídica -que el propio Marx tuvo en menteestaba destinada a completar la crítica económica. De hecho el negar que existe esa crítica jurídica ha llevado a las consecuencias más desafortunadas, entre ellas, la idea de que las relaciones capitalistas han reducido las relaciones entre las personas a relaciones entre cosas. En palabras de Fine:

[Esta interpretación] será ciertamente poco convincente para quienes pueden ver ante sus ojos que el capitalismo también trae consigo la idea de la integridad de la persona humana, la libertad individual, la igualdad ante la ley, los derechos individuales, etcétera. La crítica del aspecto materialista (i.e. económico) de la sociedad capitalista será necesariamente parcial y vulnerable si no es acompañada por una crítica de su aspecto humanista (i.e. jurídico). La crítica de la economía política debe estar integrada con una crítica de la ciencia del derecho. ${ }^{51}$

El punto de partida de dicha crítica es la propiedad privada y su idealización. En ese sentido, Marx recuerda que Hegel había tomado la propiedad privada como la célula del pensamiento legal. Dicha idealización ha llevado a entender la apropiación de la naturaleza como un medio para la vida en lugar de la realización de la individualidad. Este camino llevará a Marx a cuestionar la idea de que la propiedad privada debería ser entendida como la forma natural y racional válida para todos los tiempos. La propiedad privada es un tipo de propiedad específico de un momento histórico determinado, así, la idea de que la posesión de una propiedad puede ser el atributo de un individuo abstracto que está aislado de otros individuos es lo que conforma el núcleo del fetichismo jurídico de la modernidad ${ }^{52}$.

Con todo, Marx ve en la propiedad privada un elemento para el desarrollo de la individualidad, la crítica a ella se centra en que reposa en el trabajo alienado y en la utilización de los otros como

51- Robert Fine, Democracy and the Rule of Law...,op.cit., p. 98

52- Ver, Fine, Robert, Democracy and the Rule of Law..., op.cit., pp. 103-105 
medios. El rasgo distintivo de esto es que en el intercambio de fuerza de trabajo por salario que hace el trabajador con el capitalista se presume que hay libertad comercial. Sin embargo, para Marx lo que hay es una relación de explotación en la que el trabajador no recibe un pago por su trabajo sino por su fuerza de trabajo y una relación donde los productos de su trabajo son extraños a él.

Las características de esta forma de intercambio llevaron a filósofos como Lukács a afirmar que los trabajadores eran una mercancía y que esa condición es la que los vuelve autoconscientes de su existencia, que es lo que finalmente les permitirá la organización como clase, así como la posibilidad de tomar el poder. Al respecto, Robert Fine comenta que para Marx era la socialización del trabajo dentro del capital lo que permitía la organización de la clase trabajadora. Así, una vez organizada, la clase trabajadora comienza a entenderse no como una mera mercancía que utiliza el capitalista, sino como sujetos libres dueños de una propiedad privada muy específica: su fuerza de trabajo.

Como mencionamos párrafos atrás este postulado de Marx tiene una significación jurídica muy relevante. Esto se ve en tres aspectos: primero, si los trabajadores son dueños de una propiedad privada entonces también son co-partícipes de la riqueza común, lo que hace que su lucha por la liberación sea materializable en la arena jurídica; segundo, si los trabajadores pueden organizarse como sujetos libres y oponer su derecho al derecho establecido, entonces la ley puede ser también un escenario para la lucha de clases; tercero, que la santidad de la propiedad privada operada por la modernidad, al trasladarse al terreno del trabajador permite que se refunden los conceptos de igualdad jurídica y de libertad.

Esta interpretación de Marx parece abrirnos el camino para la construcción de un Estado de derecho en el que ni los trabajadores, ni las masas populares estén desprotegidas frente a la dinámica capitalista. Un Estado de derecho en el que se reconozca materialmente la igualdad y la libertad, esto es, un escenario jurídico donde los trabajadores no sólo tienen derechos reconocidos formalmente, sino donde tienen la posibilidad de apropiarse del derecho para exigir la materialización de esos derechos. Significativamente, esta interpretación no apunta a la creación de un Estado asistencial en el que trabajadores y masas populares quedan a la expectativa de que el Estado los asista para incluirse dentro de la dinámica jurídica y política, sino que apunta a un Estado democrático en el que la participación activa de los trabajadores en la producción de riqueza común les permite a su vez la inclusión política y jurídica. Esto ha sido un punto clave para los teóricos socialistas del derecho como el filósofo español Elías Díaz, quien establece que la participación de los trabajadores, en tanto creadores de la riqueza común, es un aspecto primordial para la construcción de un Estado democrático de derecho.

\section{Bibliografía}

Fernández Liria, Carlos y Alegre Zahonero, Luis, El Orden de El Capital, Madrid, Akal, 2010. Fine, Robert, Democracy and the Rule of Law: Marx's Critique of the Legal Form, USA, Balckburn Press, 2002.

"Marxism and the Social Theory of Law" en Law and Social Theory, Max Travers, Reza Banakar (eds.), Oregon, Hart Publishing, 2013.

Habermas, Jürgen Teoría y Praxis, Barcelona, Altaya, 1999.

Marx, Karl, Crítica a la Filosofía del Estado de Hegel, Madrid, Editorial Biblioteca Nueva, 2010. El Capital, Tomo I, Madrid, Siglo XXI, 2010. 
,Economic \& Philosophic Manuscripts of 1844, Moscow, Progress Publishers, 1959. , Escritos de juventud sobre el derecho, Madrid, Anthropos, 2008.

Miaille, Michel, El Estado del Derecho, Puebla, Universidad Autónoma de Puebla, 1985.

Negt, Oskar, Kant y Marx. Un diálogo entre épocas, Madrid, Trotta, 2004.

Pisarello, Gerardo, Un Largo Termidor, Madrid, Trotta, 2011.

Rousseau, Jean - Jacques, El Contrato Social, Madrid, Tecnos, 1988.

Shapiro, Ian, Los Fundamentos Morales de la Política, Ciudad de México, El Colegio de México, 2007. 